\title{
Cancer Susceptibility Syndromes in Childhood Cancer: Okmeydanı Experience
}

\author{
(D) Hilal Susam Şen ${ }^{1}$, (1D Süheyla Ocak² \\ 1 University of Health Sciences Turkey, Istanbul Okmeydanı Training and Research Hospital, Clinic of Pediatrics, Division of Pediatric Oncology, \\ istanbul, Turkey \\ 2istanbul University istanbul Faculty of Medicine, Department of Child Hematology and Oncology, Istanbul, Turkey
}

\section{Abstract}

Objective: Childhood cancers form 2\% of all cancers, and identified familial and genetic factors are responsible for only 5-15\%. Determining the hereditary conditions that cause predisposition enables early detection of cancer.

Methods: It was aimed to determine the patients with a genetic predisposition to cancer, treatment success and drug side effects among the patients diagnosed with a non-leukemia malignancy in Okmeydanı Training and Research Hospital between 2015-2017.

Results: A Cancer Predisposition syndrome was found in 7 (5\%) of 121 cases diagnosed with non-leukemia malignancy. Cancer Predisposition syndromes were Ataxia telangiectasia, Beckwith Wiedemann syndrome, Neurofibromatosis type 1, Down syndrome, Gardner syndrome, and Rothmund Thomson syndrome. Cancers observed were Non-hodgkin lymphoma, Wilms tumor, malignant glial tumor, malignant peripheral nerve sheath tumor, testicular germ cell tumor, hepatoblastoma, and osteosarcoma. Malignancy was detected at an early stage in all three patients who were followed up regularly due to Cancer Predisposition syndrome. At the last follow-up, five cases were in remission. In two cases, drug dose reduction was required due to chemotherapy side effects.

Conclusion: Detection of malignancy at an early stage indicates the importance of regular follow-up. With this study, we wanted to emphasize the importance of recognizing Cancer Predisposition syndromes and the need for regular follow-up.

Keywords: Childhood cancer, Cancer Predisposition syndromes, malignancy

\section{INTRODUCTION}

The first questions that come to the minds of the parents of children diagnosed with cancer are: "Is this disease caused by us, is there any possibility of it affecting other children?". Evidence of genetic susceptibility to cancer will enable us to answer these questions and provide genetic counseling. Childhood cancers make up 2-4\% of all cancers. Every year, 200.000 children under the age of 15 are diagnosed with cancer. In general, the risk for cancer development in the first 15 years of life varies between 1/600-1/1000, and most of them occur in the first five years. No specific cause can be found in $75-90 \%$ of cases. Identified familial and genetic factors are responsible for 5-15\% and known environmental contacts and exogenous factors for less than $5-10 \%$ (1). Exogenous factors are classified as external agents (physical carcinogens, ionizing radiation, non-ionizing radiation), biological carcinogens (virus infections), and chemical carcinogens (tobacco, pesticides, asbestos, aflatoxin, arsenic, food and drinking water pollutants, drugs, and medicines). Approximately $90 \%$ of all newly diagnosed cancers occur with de novo somatic mutations and $10 \%$ due to hereditary genetic features (2). There are many hereditary conditions that increase the risk of tumors in childhood and can cause a predisposition for cancer development. The frequency of cancer in children and adolescents with an underlying genetic syndrome or hereditary 
susceptibility is unclear. In the early 1990s, this rate was estimated to be 1-10\% (3). In a newer publication in the Pediatric Cancer Genome Project/St. Jude Children's Research Hospital, a frequency of $16.0 \%$ in solid tumor cases, $8.6 \%$ in brain tumors, and $3.9 \%$ in leukemia was detected (4). This report focused on 23 well-known cancer susceptibility genes and genes with a high penetration rate of 8 types of cancer. The most frequently affected genes were found to be TP53, adenomatous polyposis coli (APC), and BRCA2.

Identifying the hereditary conditions that cause predisposition provides early detection of cancer by developing screening programs. It may also lead to a change in treatment in cases of increased toxicity or resistant disease. In this study, it was aimed to determine patients with a genetic predisposition to cancer who had a diagnosis of non-leukemia childhood cancer and to determine the success of treatment and drug side effects.

\section{METHODS}

The files of 121 cases diagnosed with a non-leukemia malignancy in the Pediatric Oncology Department of Okmeydanı Training and Research Hospital between 2015 and 2017 were analyzed retrospectively. The study was performed in accordance with the ethical rules based on the principles of the Helsinki Declaration. A Cancer Predisposition syndrome was found in 5\% (7 cases) of these cases.

\section{RESULTS}

The demographic characteristics of the cases are given in Table 1. The mean age of Cancer Predisposition syndrome and cancer diagnosis was 5 and 10 years, respectively. In 3 of the cases, Cancer Predisposition syndrome and malignancy were diagnosed the same time (case 1,4,6). Malignancy was detected at an early stage (stage 1-2) in all 3 cases (case 3,5,7) who were followed up regularly due to the Cancer Predisposition syndrome. All 4 cases without follow-up applied with advanced stage (stage 3-4) malignancy. At the last control, 5 cases were in remission. In two cases, drug dose reduction was required due to chemotherapy side effects (case 1,7).

Case 1: An 11-year-old male patient, who was admitted due to shortness of breath and respiratory distress, was diagnosed with T-lymphoblastic Non-hodgkin lymphoma (NHL) by biopsy. Also, ataxic gait, sclera, and telangiectasia were detected, and cerebellar atrophy findings were seen in cranial magnetic resonance imaging (MRI) examination. Alpha-fetoprotein (AFP)

\begin{tabular}{|c|c|c|c|c|c|c|c|c|c|}
\hline Case & $\begin{array}{l}\text { Predisposing } \\
\text { syndrome }\end{array}$ & Genetic & $\begin{array}{l}\text { Family } \\
\text { history }\end{array}$ & $\begin{array}{l}\text { Regular } \\
\text { follow- } \\
\text { up }\end{array}$ & $\begin{array}{l}\text { Age at } \\
\text { diagnosis } \\
\text { of the } \\
\text { predisposing } \\
\text { syndrome }\end{array}$ & Malignity & $\begin{array}{l}\text { Age at } \\
\text { diagnosis } \\
\text { of } \\
\text { malignancy }\end{array}$ & $\begin{array}{l}\text { Chemotherapy } \\
\text { side effects } \\
\text { and drug dose } \\
\text { reduction }\end{array}$ & Outcome \\
\hline 1 & $\begin{array}{l}\text { Ataxia } \\
\text { telangiectasia }\end{array}$ & $\begin{array}{l}\text { ATM } \\
\text { mutation }\end{array}$ & - & - & 11 & $\begin{array}{l}\text { Non-Hodgkin } \\
\text { lymphoma }\end{array}$ & 11 & + & $\begin{array}{l}\text { Diseased, } \\
\text { alive }\end{array}$ \\
\hline 2 & $\begin{array}{l}\text { Beckwith } \\
\text { Wiedemann }\end{array}$ & $\begin{array}{l}\text { Clinical } \\
\text { diagnosis }\end{array}$ & - & - & 1 & Wilms' tumor & 4 & - & $\begin{array}{l}\text { Disease- } \\
\text { free, alive }\end{array}$ \\
\hline 3 & Down & $\begin{array}{l}\text { Trisomy } \\
21\end{array}$ & - & + & 1 & $\begin{array}{l}\text { Testicular germ } \\
\text { cell tumor }\end{array}$ & 14 & - & $\begin{array}{l}\text { Disease- } \\
\text { free, alive }\end{array}$ \\
\hline 4 & Gardner & $\begin{array}{l}\text { APC } \\
\text { mutation }\end{array}$ & Father + & - & 0.5 & Hepatoblastoma & 0.5 & - & $\begin{array}{l}\text { Disease- } \\
\text { free, alive }\end{array}$ \\
\hline 5 & $\begin{array}{l}\text { Neurofibromatosis } \\
\text { type } 1\end{array}$ & $\begin{array}{l}\text { Clinical } \\
\text { diagnosis }\end{array}$ & $\begin{array}{l}\text { Mother: } \\
\text { NF }+ \\
\text { pancreas } \\
\text { tumor } \\
\text { Sister: NF }\end{array}$ & + & 3 & MPNST & 13 & - & $\begin{array}{l}\text { Disease- } \\
\text { free, alive }\end{array}$ \\
\hline 6 & $\begin{array}{l}\text { Neurofibromatosis } \\
\text { type } 1\end{array}$ & $\begin{array}{l}\text { Clinical } \\
\text { diagnosis }\end{array}$ & $\begin{array}{l}\text { Mother: } \\
\text { NF } \\
\text { Sister: } \\
\text { NF+ } \\
\text { malignant } \\
\text { glial } \\
\text { tumor }\end{array}$ & - & 15 & Glioblastoma & 15 & - & $\begin{array}{l}\text { Diseased, } \\
\text { alive }\end{array}$ \\
\hline 7 & $\begin{array}{l}\text { Rothmund } \\
\text { Thomson }\end{array}$ & RECQL4 & - & + & 4 & Osteosarcoma & 13 & + & $\begin{array}{l}\text { Disease- } \\
\text { free, alive }\end{array}$ \\
\hline
\end{tabular}


level, which was screened due to suspected ataxia telangiectasia (AT), was found to be high. ATM gene mutation was detected in the genetic evaluation of the case. Also, bronchiectatic changes were observed in both lungs due to AT. T-cell lymphopenia was detected in the immunological evaluation, and treatment disruptions occurred, and drug dose reductions were made during chemotherapy since drug side effects were seen more than expected, and frequent infections were experienced. The patient, who is still partially responsive, continues to be treated.

Case 2: The patient was admitted with severe abdominal pain after being kicked in the abdominal region while joking with his brother, and a ruptured mass of about $10 \mathrm{~cm}$ in diameter from the left kidney was detected after further imaging studies. Wilms' tumor was diagnosed with a biopsy. On admission, it was learned that the patient was diagnosed with Beckwith Wiedeman syndrome (BWS) at the age of 1 due to left-sided hemihypertrophy and macroglossia, but was not followed up regularly. In the abdominal ultrasonography (USG) examination, medullary nephrocalcinosis was detected in the other kidney, and the patient was scheduled for follow up by the nephrology department. The treatment of the patient who underwent tumor resection after preoperative chemotherapy was completed with postoperative radiotherapy and chemotherapy. The patient is in remission for one year.

Case 3: A 14-year-old male patient who was taken to regular follow-up examinations since the age of 1 with the diagnosis of Down syndrome was admitted with swelling in the right testicle. The patient had no distant organ metastasis, and he was diagnosed with stage 1 non-seminamatous mixed germ cell tumor after high orchiectomy. Chemotherapy was given after surgical treatment. The patient whose treatment is completed is remission for two years.

Case 4: A 6-month-old male patient with a paternal history of Gardner's syndrome was admitted with increasing abdominal swelling for the last two months. After abdominal MRI examination, multifocal masses were seen in the liver, and hepatoblastoma was diagnosed by biopsy. After genetic evaluation, APC mutation was detected. Liver transplantation was performed in the patient who was given preoperative chemotherapy and was not found suitable for the surgery. He is in remission without treatment for two years.

Case 5: A 13-year-old girl who was followed up with the diagnosis of neurofibromatosis (NF) type 1 was admitted due to the rapid growth of the previous neurofibroma in the neck area. After mass excision, the diagnosis of malignant peripheral nerve sheath tumor (MPNST) was made. The patient who was given postoperative chemotherapy is in remission without treatment for two years.

Case 6: A 15-year-old girl with an older sister with a malignant glial tumor presented with a complaint of seizure and a mass in the left frontal region was detected in the cranial MRI examination. A diagnosis of malignant glial tumor was made after mass excision. NF type 1 was considered by seeing cafe au lait spots on the patient, her mother, and her older sister, and the genetic examination continues. Postoperative radiotherapy and chemotherapy were given, and she is followed-up in remission for three months.

Case 7: A 13-year-old male patient who was followed-up due to Rothmund Thomson syndrome (RTS) was brought with the complaint of left knee swelling. MRI examination revealed a mass of left distal femur origin, and a diagnosis of osteosarcoma was made after pathological evaluation. When giving preoperative chemotherapy, especially after Doxorubicin treatments, increased signs of toxicity were observed, and dose reduction was made. After dose reduction, chemotherapy was continued without disruption. Postoperative chemotherapy was completed in the patient with a tumor necrosis rate of $>90 \%$ (good chemotherapy response) in the postoperative pathological evaluation, and he is being followed up for six months without treatment.

\section{DISCUSSION}

It is a fact that cancers are caused by genetic mutations. For many childhood cancers, when age, occurrence, and cell origin are evaluated, they appear to indicate an intrauterine origin. Pediatric oncologists should evaluate children diagnosed with cancer and their families according to well-defined criteria for hereditary cancer susceptibility (5). Rare tumors associated with cancer susceptibility (adrenocortical carcinoma), bilateral or multifocal tumors (Wilms' tumor), tumors that occur earlier than expected (thyroid carcinoma), multiple synchronic, or metachronous tumors, additional symptoms for the underlying syndrome (axillary freckle) and family history should be examined. Also, the same or related cancers occurring in the same family, a cancer diagnosis in two or more first-degree relatives, tumors associated with a specific cancer susceptibility syndrome, young age, cancer in siblings, and consanguineous marriages should suspect the physician.

Many hereditary immune deficiency syndromes increase the risk of childhood cancer, especially lymphomas and leukemia. Because they are rare, they make up less than $0.1 \%$ of all childhood cancers. AT is the most common, and more than 
$10 \%$ of affected children develop lymphoma or leukemia before the age of 15 (6). Bloom syndrome, common variable immunodeficiency syndrome, X-linked agammaglobulinemia, immunoglobulin A deficiency, severe combined immune deficiency, Duncan disease, and Nijmegen Breakage syndrome are at high risk of NHL and leukemia. In our series, similar to the literature, NHL developed in a 14-year-old male who was not previously diagnosed with AT. Although the drug doses to be given in Chromosomal Breakage syndromes are also controversial in the literature, the general belief is to start the treatment with a full dose and to reduce the dose if the side effects are seen more (7). In our case, full-dose treatment was initiated without drug reduction. In our case, whose chemotherapy side effects were severe, dose reduction was made in the following cycles, and treatment disruptions were observed. In the literature, it has been reported that dose reduction does not lead to a disadvantage in disease control in patients with chromosomal breakage syndromes, and severe infections are prevented by reducing systemic toxicity (7).

The most common Overgrowth syndrome associated with childhood cancer is BWS, and the cumulative risk of cancer is $10 \%$ by age 4 . Wilms' tumor is the most common cancer in BWS. Also, the risk of hepatoblastoma, neuroblastoma, and pancreatoblastoma is increased (8). Our patient was diagnosed with BWS at the age of 1 , Wilms' tumor was diagnosed at an advanced stage as the patient was not taken to regular followups. Screening is recommended at regular intervals in BWS cases (Table 2). The absence of follow-ups led to the development of malignancy and the inability to treat medullary nephrocalcinosis, which is one of the other findings in BWS. This situation may cause chronic kidney failure in the long term in our case with a single kidney. Wilms' tumor is one of the best treatment successes among childhood malignancies. Recognizing BWS and other diseases that predispose to Wilms' tumors (WAGR syndrome, Denys Drash syndrome, isolated hemihypertrophy, Bloom syndrome) and follow-up will provide treatability with early diagnosis.

Numerical chromosome abnormalities are associated with childhood cancer, among which the largest number of cases has been reported in Down syndrome to date (9). In addition to the increase in the frequency of leukemia, an increase in the frequency of germ cell tumors has also been proven. However, the frequency of solid tumors other than lymphoma and retinoblastoma is not seen in children with Down syndrome. Although seminoma is reported more frequently with Down syndrome, non-seminomatous germ cell tumor in our case is a different feature from the literature. Our patient's regular follow-up from the age of 1 caused the early detection of cancer.

Gardner's syndrome, a variant of familial adenomatous polyposis, is an autosomal dominant disease characterized by malignant altered colon polyps and benign and malign extracolon lesions. Tumors frequently associated with Gardner's syndrome are carcinoma of the ampulla of Vater, papillary thyroid carcinoma, and hepatoblastoma in childhood. The frequency of hepatoblastoma has been reported as 1.5\% (10). Family screening is required because of the autosomal dominant inheritance of the disease (11). In cases with genetically diagnosed Gardner syndrome, especially in the first five years of life, abdominal USG and AFP screening are recommended every six months. Our case has been followed up in remission for two years after liver transplantation and is being followed up for other malignancies that may accompany.

NF1 is an autosomal dominant inheritance, which is the most common familial tumor predisposition syndrome that develops as a result of the mutation in the NF1 gene located in chromosome 17 and is the most common in the society. Due to its predisposition to benign and malignant tumor development and NF1 related complications, early diagnosis and clinical follow-up are essential (12). Malignant tumors that may develop in NF1 are glial central nervous system tumors, MPNST, sarcomas, myeloid leukemia, myelodysplasia, and myeloproliferative disorders (12). In our series, MPNST and malignant glial tumors were observed in our two NF1 cases. Regular follow-up of our case with MPNST enabled early detection and treatment of malignant transformation in neurofibroma. The patient with a malignant glial tumor was admitted with advanced disease because the patient was not followed-up regularly despite having an anamnesis in the family. Close monitoring of children with NF1 will allow early detection of malignant tumors.

RTS is a syndrome of childhood cancer-associated autosomal recessive DNA repair disorders, and other diseases in this group are Fanconi anemia, AT, Bloom syndrome, Nijmegen Breakage syndrome, and xeroderma pigmentosum (13). RTS increases the frequency of skin cancer and osteosarcoma. In the largest series in which RTS cases were reported, 32\% of the cases developed osteosarcoma at the age of 11.5 years (14). Hicks et al. (15) reported that increased toxicity due to doxorubicin could be observed in RTS cases. However, the general recommendation is to give the full dose of the treatment and reduce the dose in case of increased toxicity (16). In our case, a full dose of chemotherapy was initiated, and the patient showed signs of 


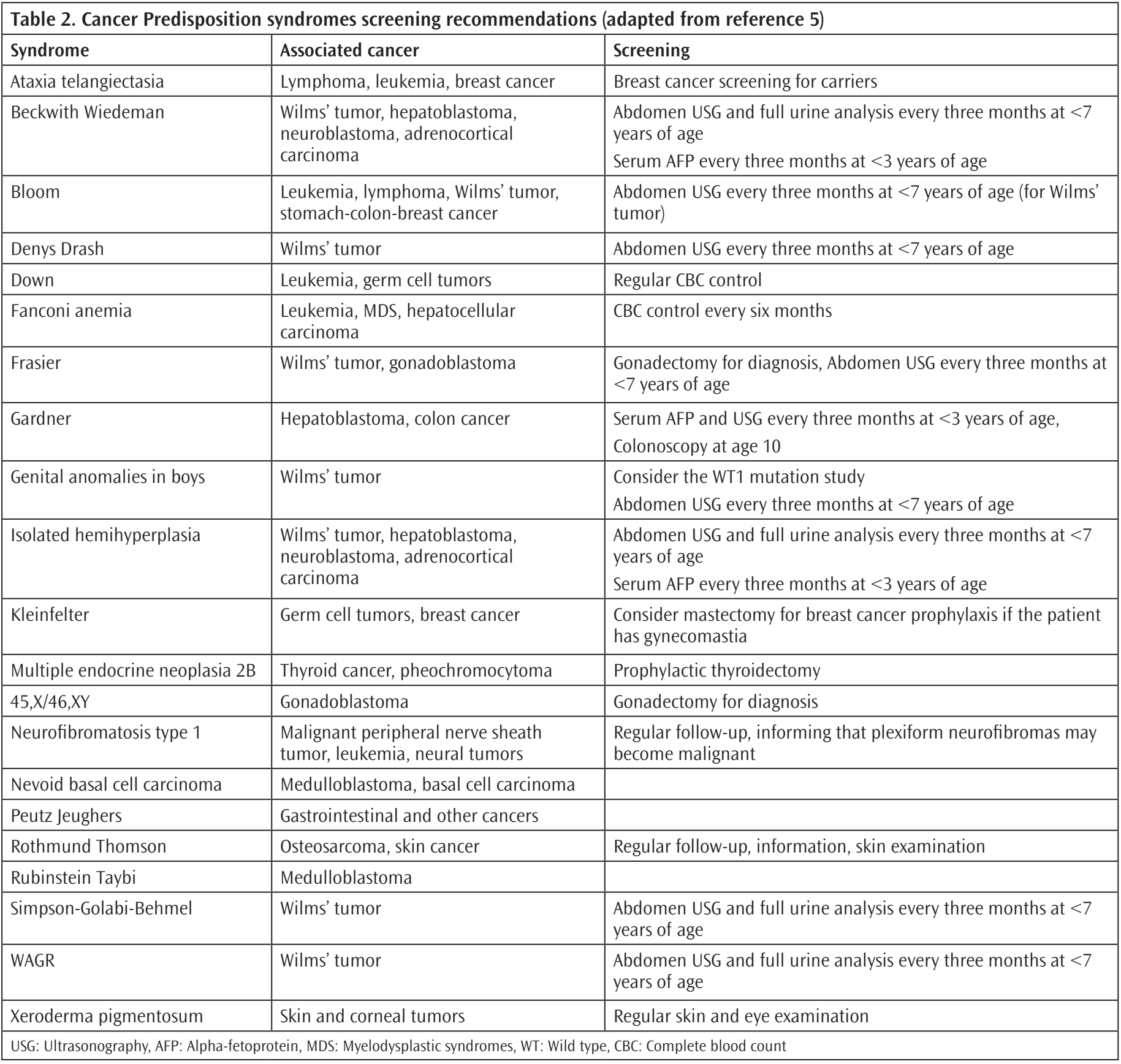

toxicity due to doxorubicin similar to Hicks et al. (15) After dose reduction, chemotherapy was completed without disruption.

\section{CONCLUSION}

It is an important feature to detect the cases that are regularly followed up in our series at an early stage and shows the importance of regular follow-up. Also, with the determination of hereditary conditions that cause predisposition, the treatment dose was successfully completed by reducing the drug dose in
2 of our patients who showed increased signs of toxicity due to chemotherapy. In the light of these findings, with this study, we wanted to emphasize the importance of recognizing diseases that predispose to cancer and the need for regular follow-up.

\section{Ethics}

Ethics Committee Approval: The study was analyzed retrospectively in accordance with the ethical rules based on the principles of the Helsinki Declaration between 2015 and 2017 by Department of Okmeydanı Training and Research Hospital. 
Informed Consent: Informed consent was obtained from patients' parents.

Peer-review: Externally peer-reviewed.

\section{Authorship Contributions}

Surgical and Medical Practices: H.Ș., S.H., Concept: H.Ş., Design: H.Ş., S.H., Data Collection or Processing: H.S., Analysis or Interpretation: H.Ş., Literature Search: H.Ş., S.O., Writing: H.Ş., S.O.

Conflict of Interest: No conflict of interest was declared by the authors.

Financial Disclosure: The authors declared that this study received no financial support.

\section{REFERENCES}

1. Lichtenstein P, Holm NV, Verkasalo PK, Iliadou A, Kaprio J, Koskenvuo M, et al. Environmental and heritable factors in the causation of cancer-analyses of cohorts of twins from Sweden, Denmark, and Finland. N Engl J Med 2000;13:78-85.

2. Stiller CA . Epidemiology and genetics of childhood cancer. Oncogene 2004;23:6429-44.

3. Narod SA, Stiller C, Lenoir GM. An estimate of the heritable fraction of childhood cancer. Br J Cancer 1991;63:993-9.

4. Walsh M, Wu G, Edmonson M, Gruber TA, Easton J, Yergeau D, et al. Incidence of germline mutations in cancer-predisposition genes in children with hematologic malignancies: a report from the pediatric cancer genome Project. N Engl J Med 2015;373:2336-46.

5. Knapke S, Zelley K, Nichols KE, KohImann W, Schiffman JD. Identification, management, and evaluation of children with cancer-predisposition syndromes. Am Soc Clin Oncol Educ Book 2012;576-84.
6. Morrell D, Cromartie E, Swift M. Mortality and cancer incidence in 263 patients with ataxia-telangiectasia. J Natl Cancer Inst 1986;77:89-92.

7. Bienemann K, Burkhardt B, Modlich S, Meyer U, Möricke A, Bienemann $\mathrm{K}$, et al. Promising therapy results for lymphoid malignancies in children with chromosomal breakage syndromes (Ataxia teleangiectasia or Nijmegen-breakage syndrome): a retrospective survey. $\mathrm{Br}$ J Haematol 2011;155:468-76.

8. DeBaun MR, Tucker MA. Risk of cancer during the first four years of life in children from The Beckwith-Wiedemann Syndrome Registry. J Pediatr 1998;132:398-400.

9. Hasle $\mathrm{H}$, Clemmensen IH, Mikkelsen M. Risks of leukaemia and solid tumours in individuals with Down's syndrome. Lancet 2000;355:165-9.

10. Gruner BA, DeNapoli TS, Andrews W, Tomlinson G, Bowman L, Weitman SD. Hepatocellular carcinoma in children associated with Gardner syndrome or familial adenomatous polyposis. J Pediatr Hematol Oncol 1998;20:274-8.

11. Fotiadis C, Tsekouras DK, Antonakis P, Sfiniadakis J, Genetzakis M, Zografos GC. Gardner's syndrome: A case report and rewiev of the literature. World J Gastroenterol 2005;11:5408-11.

12. Varan A, Șen H, Aydın B, Yalçın B, Kutluk T, Akyüz C. Neurofibromatosis type 1 and malignancy in childhood. Clin Genet 2016;89:341-5.

13. Kuhlen M, Borkhardt A. Cancer susceptibility syndromes in children in the area of broad clinical use of massive parallel sequencing. Eur J Pediatr 2015;174:987-97.

14. Wang LL, Levy ML, Lewis RA, Chintagumpala MM, Lev D, Rogers M, et al. Clinical manifestations in a cohort of 41 Rothmund-Thomson syndrome patients. Am J Med Genet 2001;102:11-7.

15. Hicks MJ, Roth JR, Kozinetz CA, Wang LL. Clinicopathologic features of osteosarcoma in patients with Rothmund-Thomson syndrome. J Clin Oncol 2007;25:370-5.

16. Zils K, Klingebiel T, Behnisch W, Mueller HL, Schlegel PG, Fruehwald $\mathrm{M}$, et al. Osteosarcoma in patients with Rothmund-Thomson syndrome. Pediatr Hematol Oncol 2015;32:32-40. 